\title{
Sound Absorption Rate and Sound Transmission Loss of CLT Wall Panels Composed of Larch Square Timber Core and Plywood Cross Band ${ }^{1}$
}

\author{
Chun Won $\mathrm{Kang}^{2} \cdot$ Sang Sik Jang $\mathbb{D}^{3, \dagger} \cdot \mathrm{Ho}$ Yang $\mathrm{Kang}^{3} \cdot$ Chengyuan $\mathrm{Li}^{4}$
}

\begin{abstract}
The square timbers of larch having cross section of $90 \mathrm{~mm} \times 90 \mathrm{~mm}$ were glued laterally to be formed $1,200 \mathrm{~mm} \times$ 2,400 mm panels which were used as cores for CLT wall panels. Then, structural plywood panels having size of $1,200 \mathrm{~mm}$ $\times 2,400 \mathrm{~mm}$ were used as cross band covering the small square timber cores to manufacture CLT wall panels. The sound absorption rate of CLT wall panels and polyester board attached CLT wall panels were investigated. The mean sound absorption coefficients of the former and the latter in the frequency range of 100-6400 Hz were $0.21 \mathrm{and} 0.74$, respectively. The noise reduction coefficients (NRC) of those were 0.21 and 0.40 , respectively. Also, the mean sound transmission loss of CLT wood panel in the frequency range of $50-1600 \mathrm{~Hz}$ was $45.12 \mathrm{~dB}$ and that value at the frequency of $500 \mathrm{~Hz}$ was $42.49 \mathrm{~dB}$. It was suggested that the polyester board attached CLT wall panels could be used as housing wall because of its high sound absorption rate and high sound transmission loss.
\end{abstract}

Keywords: sound absorption coefficient, sound transmission loss, CLT wall panels

\section{INTRODUCTION}

The larch (Larix kaempferi) wood come from small diameter logs is used as pallet or fuel wood in Korea though it has relatively high mechanical properties such as bending strength and modulus of elasticity in bending etc. This study was started to investigate the possibility of using small larch logs for more effective usages than pallet or fuel. One of such efficient utilization is the structural member for construction of timber buildings.
CLT (cross laminated timber) construction has become a new trend in the world, and more people in Korea also have interest in CLT construction. Therefore, it looks a good idea to investigate the possibility of using small larch logs for CLT manufacturing. To increase the possibility of using small larch logs for CLT manufacturing, the expenses for processing of small larch logs and manufacturing of CLT panels shall be minimized. For these purposes, small larch logs were sawn four sides, dried and planed to small square timbers

\footnotetext{
${ }^{1}$ Date Received August 16, 2018, Date Accepted December 21, 2018

2 Department of Housing Environmental Design, and Research Institute of Human Ecology, College of Human Ecology, Chonbuk National University, Jeonju 54896, Republic of Korea

${ }^{3}$ Department of Forest Products, College of Agriculture \& Life Sciences, Chungnam National University, Daejeon 34134 , Republic of Korea

${ }^{4}$ Department of Forest Products, College of Agriculture \& Life Sciences, Beiwha University, China

† Corresponding author: Sang-Sik Jang (E-mail: ssjang@cnu.ac.kr, ORCID: 0000-0002-3124-7044)
} 


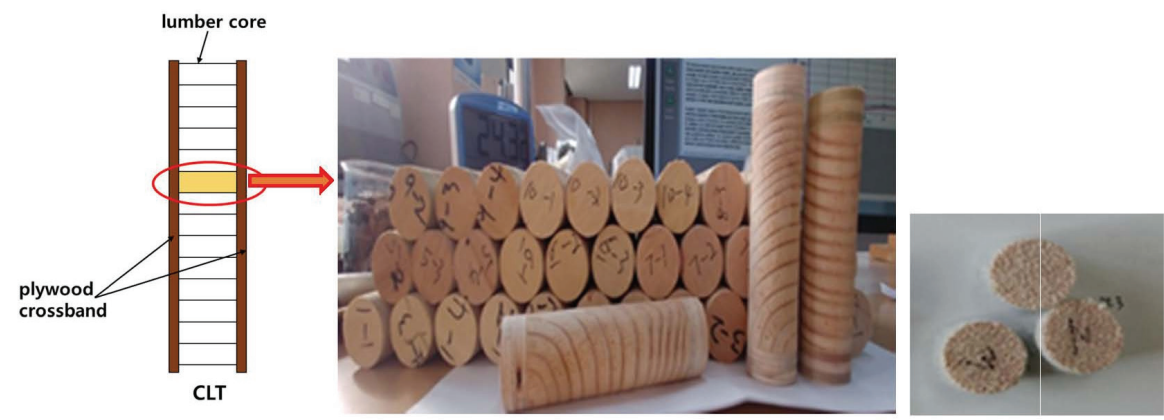

Fig. 1. Specimens for sound absorption rate measurement (left, CLT; light, polyester board).

having section size of $90 \mathrm{~mm} \times 90 \mathrm{~mm}$. These small square timbers were glued together laterally to form core panel, and 1,200 $\mathrm{mm} \times 2,400 \mathrm{~mm}$ plywood panels were used to cover both surfaces of this core panel to form CLT of the size $1,200 \mathrm{~mm} \times 2,400 \mathrm{~mm}$,

In the view of acoustical properties of construction materials, (Jang et al., 2018; Kang et al., 2018a; Kang et al., 2018c; Kim et al., 2012; Kim et al., 2015; Kook et al., 2007; Whang et al., 2010) the acoustic properties of board material are well defined in terms of absorption, reflection, impedance and transmission loss. The soundabsorbing materials commonly used in construction include porous materials such as glass wool, gypsum, and similar materials (Kim, 2007).

In this study, to estimate the sound absorption rate and sound transmission loss of CLT panels, small larch square timbers with $90 \mathrm{~mm} \times 90 \mathrm{~mm}$ cross section, which were glued laterally to form core panels and $12 \mathrm{~mm}$ thick plywood panels were used as cross bands to make three-ply CLT wall panels on opposing both surfaces and the backs of larch square timber core panels, then the sound absorption capability and sound transmission loss of normal CLT wall panels were investigated, and the sound absorption capability compared with those results of polyester based board attached CLT wall panels. From these results, the acoustical usability of CLT wall panels was discussed.

\section{MATERIALS and METHODS}

\subsection{Specimen preparation}

In this study, small diameter larch logs having diameter of $120 \mathrm{~mm} \sim 150 \mathrm{~mm}$ were selected, and they were sawn, dried and planed to the square timbers having cross section of $90 \mathrm{~mm} \times 90 \mathrm{~mm}$. These small square timbers were glued laterally with the acetylated vinyl based adhesive to be formed 1,200 mm $\times 2,400 \mathrm{~mm}$ panels which were used as cores for CLT wall panels. Then, structural plywood panels having size of 1,200 $\mathrm{mm} \times 2,400 \mathrm{~mm}$ were used as cross band covering the surfaces and the backs of small square timber cores to manufacture CLT wall panels. From these CLT panels, the cylindrical sample specimens for measuring sound absorption coefficients with $28.9 \mathrm{~mm}$ in diameter and $110 \mathrm{~mm}$ length and for measuring sound transmission loss with $99.0 \mathrm{~mm}$ in diameter and 110 $\mathrm{mm}$ length were prepared. The mean of apparent density and moisture content of CLT sample specimens were $0.52 \mathrm{~g} / \mathrm{cm}^{3}$ and $8.15 \%$, respectively.

\subsection{Sound absorption rate measurement}

The sound absorption rate of normal and polyester board attached CLT wall panels were measured by two microphone transfer function method using impedance 


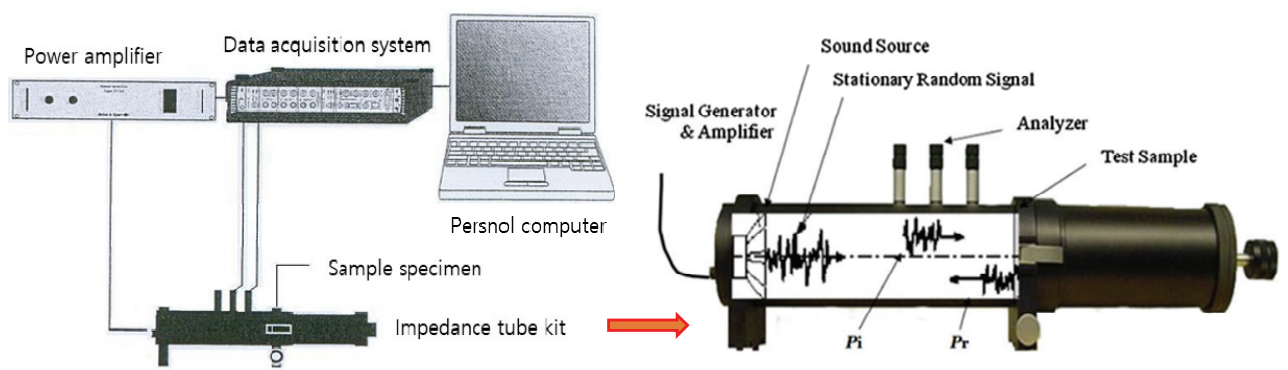

Fig. 2. Sound absorption estimation apparatus.
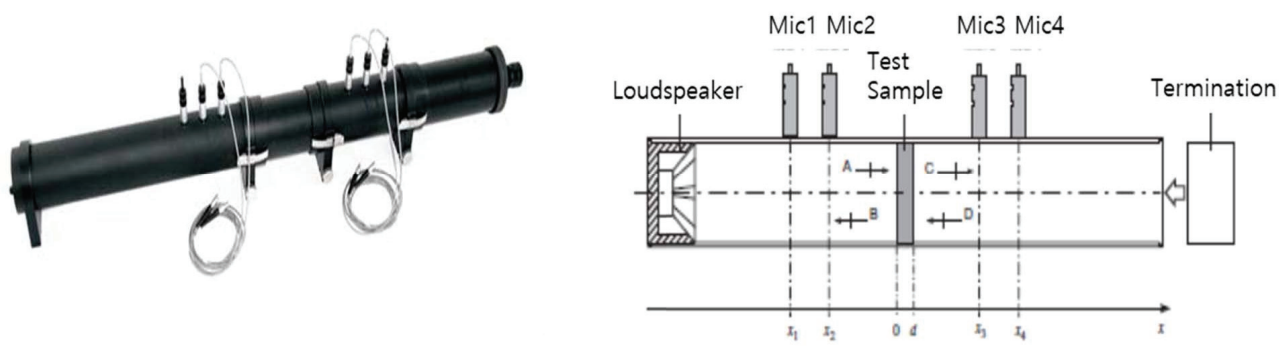

Fig. 3. Impedance tube for measuring sound transmission loss (Left, photograph; Right, schematic diagram).

tube kit (B\&K company, type 4706), pulse analysis software and a spectrum analyzer (B\&K company), as shown in Fig. 2 (Kang et al., 2010; Kang et al., 2012).

In this study, to estimate effect of polyester board attaching on CLT panels, the sound absorption rates of $25 \mathrm{~mm}$ thick polyester board with apparent density of 0.06 attached were measured in the frequency range of $100 \mathrm{~Hz} 6400 \mathrm{~Hz}$. During measurement, temperature, relative humidity, atmospheric pressure, the velocity of sound, air density and acoustic impedance were 22 . $2^{\circ} \mathrm{C}, 41.00 \%, 1017.25 \mathrm{hP}, 344.52 \mathrm{~m} / \mathrm{s}, 1.198 \mathrm{~kg} / \mathrm{m}^{3}$ and $412.70 \mathrm{~Pa} /(\mathrm{m} / \mathrm{s})$, respectively.

\subsection{Measuring acoustic transmission loss using transfer matrix method}

According to ASTM E 2611-09, specimen was placed on the middle part of the impedance tube as shown in Fig. 3. Transfer matrix method uses the impedance tube which has the sound source part and the sound receiving part and the sample holder is inserted between the two parts as shown in Fig. 3 (Kang et al., 2018b). Total 4 microphones were prepared and the two microphones per each one side and the other side were attached on the impedance tube. The sound transmission loss is calculated from the transfer functions which obtained from each of two microphones on the both sides of the impedance tube. During measurement, the frequency band was $50-1600 \mathrm{~Hz}$, the temperature and the atmospheric pressure were $23^{\circ} \mathrm{C}, 1013.5 \mathrm{hPa}$, respectively.

\section{RESULTS and DISCUSSION}

\subsection{Sound absorption rate of CLT}

The sound absorption rates of normal CLT wall panels in the frequency range of $100 \mathrm{~Hz}-6400 \mathrm{~Hz}$ are shown in Fig. 4. The X-axis represented the estimated frequency, and the $\mathrm{Y}$-axis represented the sound absorption rate. 


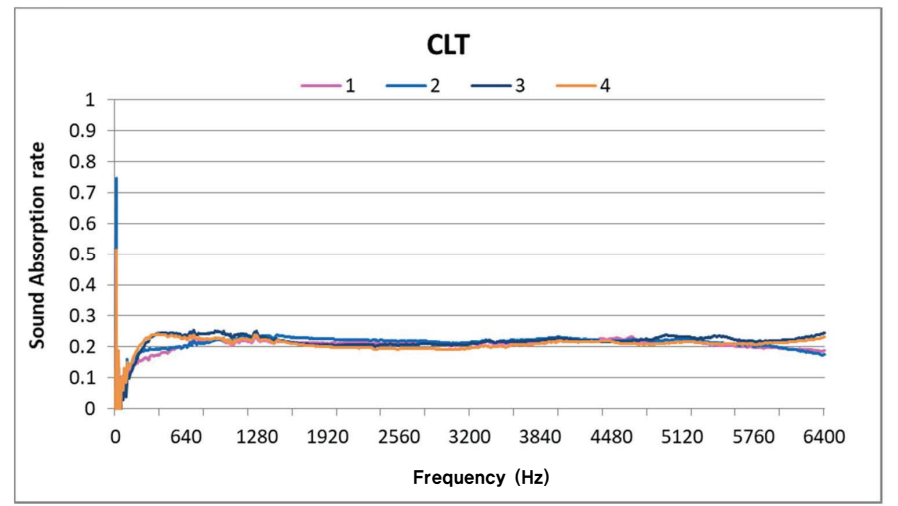

Fig. 4. Sound absorption rate of CLT wall panels (Graph legend values denote specimen numbers).

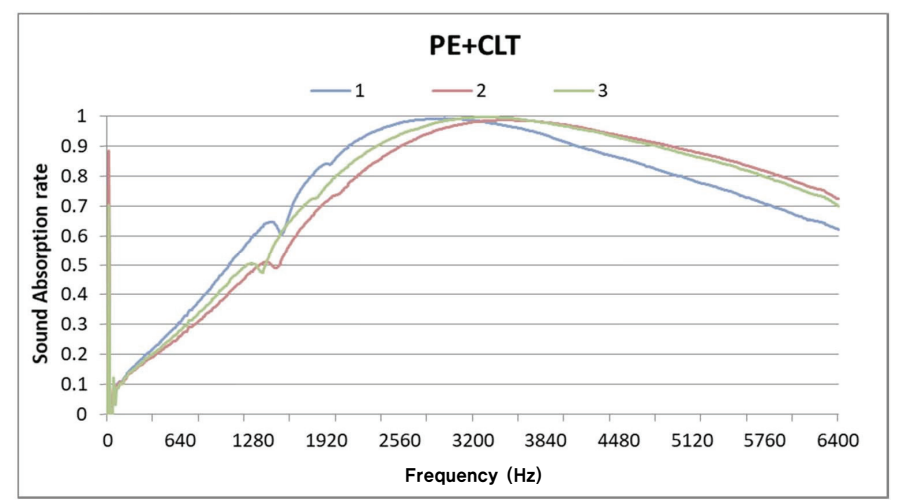

Fig. 5. Sound absorption rate of polyester board attached CLT wall panels (Graph legend values denote specimen numbers).

The highest value of normal CLT wall panels was 0.25, indicating a mean sound absorption ratio of 0.21 in the entire estimaed frequency range. The sound absorption rate of the CLT was relatively low in the whole estimated frequency range and the noise reduction coefficient was about 0.21 .

On the contrary, the sound absorption rate of polyester board attached CLT wood panels was over 4 times higher than that of normal CLT wood panels in the frequency range of $2000-4000 \mathrm{~Hz}$ as showed in Fig. 5.

The sound absorption rate of polyester board attached CLT wood specimens was increasing with increasing of frequency, which is a typical characteristic of porous sound absorber. (Kang et al., 2011; Kang et al., 2012c) The sound absorption rate of polyester board attached CLT wood panels was 0.4 at $1000 \mathrm{~Hz}, 0.35$ at 1000 $\mathrm{Hz}, 0.6-0.8$ at $2000 \mathrm{~Hz}$, and more than 0.9 at 2500-4000 Hz. The NRC (Noise Reduction Coefficient) was 0.40, which was higher than that of the commercial $11 \mathrm{~mm}$ thick gypsum board (0.28), which was frequently used as sound absorbing material for office ceiling. It can be concluded that the polyester board attached CLT wood panels could be used as acoustic housing wall materials because of its high sound absorption rates. 
Sound Absorption Rate and Sound Transmission Loss of CLT Wall Panels Composed of Larch Square Timber Core and Plywood Cross Band

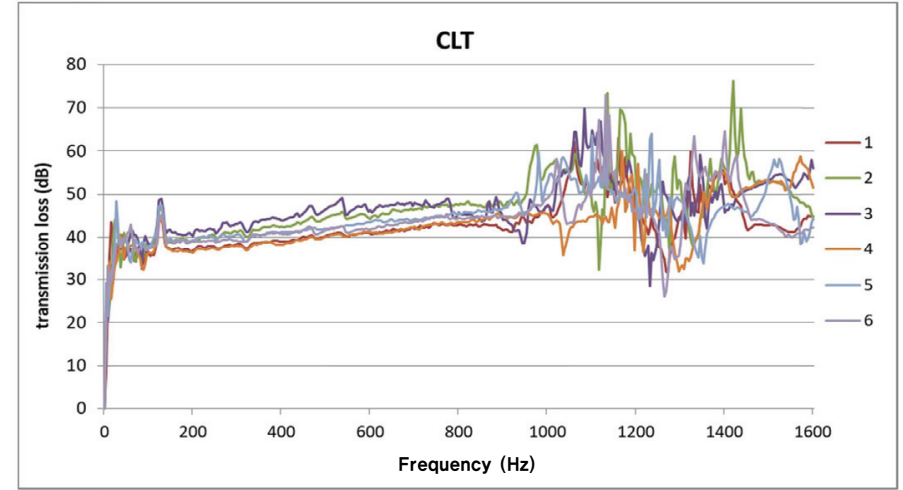

Fig. 6. Sound transmission loss of CLT wall panels (Graph legend values denote specimen numbers).

\subsection{Sound transmission loss of CLT}

When the sound transmission loss was measured, the diameter of impedance tube was limited by frequency, the diameter was $29 \mathrm{~mm}$ for high frequency range and $99 \mathrm{~mm}$ for low frequency range. (Kang et al., 2018b) In this study, the sound transmission loss was measured only in a range of 50 1600 Hz using the impedance tube with the diameter of $99 \mathrm{~mm}$ for low frequency range because the thickness of CLT sample specimen for measuring transmission loss, 110 $\mathrm{mm}$ exceed $70 \mathrm{~mm}$, the maximum capacity of sample holder.

The transmission loss of the CLT was increased as the frequency was increasing. The transmission loss of the $110 \mathrm{~mm}$ thick CLT with the density of 0.75 $\mathrm{g} / \mathrm{cm}^{3}$ was about $35 \mathrm{~dB}$ for frequencies less than 400 $\mathrm{Hz}$, over $40-45 \mathrm{~dB}$ for frequencies up to $800 \mathrm{~Hz}$, and $50 \mathrm{~dB}$ for a frequency of $1000 \mathrm{~Hz}$, thus, above the frequency of $1000 \mathrm{~Hz}$, it was about $50 \mathrm{~dB}$, and above the frequency of $1400 \mathrm{~Hz}$, it showed above $50 \mathrm{~dB}$. The mean sound transmission loss of CLT wood panel in the frequency range of $50-1600 \mathrm{~Hz}$ was $45.12 \mathrm{~dB}$ and that value at the frequency of $500 \mathrm{~Hz}$ was $42.49 \mathrm{~dB}$. According to the regulation of the Ministry of Land in Korea, the transmission loss coefficient of the sound barrier for roads should exceed $25 \mathrm{~dB}$ for a frequency of $500 \mathrm{~Hz}$; in this study, the corresponding values of the CLT wall panel were $42.49 \mathrm{~dB}$ for $500 \mathrm{~Hz}$. Here, we expected the $110 \mathrm{~mm}$ thick CLT could be used as sound insulation materials due to its high sound transmission loss.

\section{CONCLUSION}

In order to estimate the possibility of improving acoustical properties and to estimate the sound insulation capability of CLT wood panels, sound absorption property of normal and polyester board attached CLT wood panels were measured by the two microphone transfer function method and sound transmission loss of CLT wood panel was measured by the four microphone transfer matrix method. The results of this study were as follows:

1. The sound absorption rate of normal CLT wood panels showed relatively low value in almost all frequency range.

2. The sound absorption rate of polyester board attached CLT wood panels showed high value in almost all frequency range.

3. The polyester board attached CLT wood panels could be used as acoustical housing wall materials 
because of its high sound absorption rates.

4. The sound transmission loss of the CLT showed over $30 \mathrm{~dB}$ in almost all frequency range, therefore, this kind of panel is expected to be used as sound insulation wall.

\section{ACKNOWLEDGMENT}

This study was carried out with the support of 'R\&D Program for Forest Science Technology (Project No. 2017050C10-1719-BB02)' provided by Korea Forest Service (Korea Forestry Promotion Institute).

\section{REFERENCES}

ASTM E2611-09 Standard Test Method for Measurement

of Normal Incidence Sound Transmission of Acoustical Materials Based on the Transfer Matrix Method.

Hwang, S.-M., Kim, J.-D., Kwon, H, Seo, Y.-S. 2013. Sound Transmission Loss through Double Walls. International Journal of Naval Architecture and Ocean Engineering 50(2): 64-68.

Jang, E.-S., Kang, C.-W., Kang, H.-Y., Jang, S.-S. 2018. Sound Absorption Property of Traditional Korean Natural Wallpaper (Hanji). Journal of the Korean Wood Science and Technology 46(6): 703-712.

Kang, C.-W., Jang, E.-S., Jang, S.-S., Kang H.-Y. 2018a. Comparison of Transfer Function Method and Reverberation Room Method in Measuring the Sound Absorption Coefficient of Rice Straw Particle Mat. Journal of the Korean Wood Science and Technology 46(4): 362-367

Kang, C.-W., Jang, E.-S., Jang, S.-S., Kang, H.-Y. 2018b. Measurement of Sound Transmission Loss in a Sound Barrier Filled with the Rice-Straw Particles by the Transfer Function and Laboratory Measurement Methods. Journal of the Korean Wood Science and Technology 46(4): 338-345
Kang, C.-W., Kim, G.-C., Park, H.-J., Lee, N.-H., Kang, W., Matsumura, J. 2010. Changes in permeability and sound absorption capability of yellow poplar wood by steam explosion treatment. Journal of the Faculty of Agriculture, Kyushu University 55(2): 327-332.

Kang, C.-W., Lee, Y.-H., Kang, H.-Y., Kang, W., Xu, H.-R., Chung, W.-Y. 2011. Radial variation of sound absorption capability in the cross sectional surface of yellow poplar wood. Journal of the Korean Wood Science and Technology 39(4): 326332

Kang, C.-W., Li, C., Jang, E.-S., Jang, S.-S., Kang, H.-Y. 2018c. Changes in sound absorption capability and air permeability of Malas (homaliumfoetidum) specimens after high temperature heat treatment. Journal of the Korean Wood Science and Technology 46(2): 149-154.

Kang, C.-W., Oh, S.-W., Lee, T.-B., Kang, W., Matsumura, J. 2012. Sound absorption capability and mechanical properties of a composite rice hull and sawdust board. Journal of Wood Science 8: 273-278.

Kang, C.-W., Park, H.-J., Jeon, S.-S. 2012. Sound absorption capability and bending strength of Miscanthus particle based board. Journal of the Korean Wood Science and Technology 40(1): 38-43.

Kim, C.-W., Chang, T.-C., Kim, D.-S. 2012. Characteristics Analysis of Highway Traffic Noise. Transactions of the Korean Society of Noise and Vibration Engineering 22(12): 1191-1198.

Kim, D.-R., Kim, T.-M., Kim, J.-T., Park, G.-H., Ryu, L.-O. 2015. A Study on Sensitivity of Transmission Loss using Scaled Reverberation Chamber. Transactions of the Korean Society of Noise and Vibration Engineering 2015(4): 937-943.

Kim, J.-S. 2007. Characteristics of sound from construction equipment machinery room International Journal of Air-Conditioning and Refrigeration 36(1): 19-25. 
Sound Absorption Rate and Sound Transmission Loss of CLT Wall Panels Composed of Larch Square Timber Core and Plywood Cross Band

Kook, J.-H., Jung, C.-W., Yun, J.-H., Kim, J.-S. 2007. Experimental Study on Wall Sound Transmission Loss at Construction Equipment Machinery Room. Transactions of the Korean Society of Noise and Vibration Engineering 2007(3): 695-699.
Lee, J.-H., Kim, B.-S., Kim, K.-J. 2011. Study of Sound Transmission Characteristics of using a Scale Reverberation Chamber and vibro acoustic FEM. Transactions of the Korean Society of Noise and Vibration Engineering 2011(10): 92-95. 